\title{
REVIEWS
}

\section{Influence of Essential Oils on Infectious Agents}

${ }^{1}$ Department of Pharmaceutical Microbiology and Parasitology, Wroclaw Medical University, Poland

${ }^{2}$ Department of Microbiology, Wroclaw Medical University, Poland

A - research concept and design; $\mathbf{B}$ - collection and/or assembly of data; $\mathbf{C}$ - data analysis and interpretation;

$\mathbf{D}$ - writing the article; $\mathbf{E}$ - critical revision of the article; $\mathbf{F}$ - final approval of article

\begin{abstract}
Essential oils are substances of plant origin used to produce cosmetics, to preserve and aromatize food. Recently, they have become more popular among scientists and doctors due to their germicidal, antifungal, antiviral and anti-parasitic properties. As a consequence, essential oils are regarded as the source of new therapeutic substances. Numerous publications have been written regarding their effect on microorganisms in vitro. There have also been reports regarding their use in therapy as an additive to the traditional medical treatment. Essential oils may have other properties with positive effect on health because they may have an influence on the central nervous system and human mental state. It should be, however, kept in mind that compounds of essential oils might also have side effects and lead, like antibiotics, to the selection of resistant pathogens. It is necessary to develop quality standards of obtaining and using these plant preparations, so that they may provide safe and effective assistance in the fight against human pathogens (Adv Clin Exp Med 2016, 25, 5, 989-995).
\end{abstract}

Key words: essential oils, phytotherapy, alternative therapy.

Essential oils are mixtures of volatile compounds of plant origin. They are classified as secondary metabolites. They are a part of the defense system of higher plants and they also have additional protective functions $[1,2]$. Active compounds of essential oils belong to monoterpenes, sesquiterpenes, phenylpropanoids and coumarins. Mixtures of these phyto-compounds are usually extracted using steam distillation from plants' flowers, buds, leaves, fruits, seeds, rind, wood or roots [3]. The obtained extracts and their individual compounds are used as additives to cosmetics and perfumes, and to aromatize and preserve food $[4,5]$. Recently, they have been also used in phytotherapy as an alternative supplementation to traditional medical treatment, because compounds of many oils, as reported in in vitro studies, present germicidal, antifungal, antiviral and anti-parasitic properties [6, 7]. For this reason, essential oils are perceived as a source of new medical substances. Studies on their influence on pathogenic germs are significant, especially at a time when microorganisms are becoming increasingly resistant to medicines and this resistance spreads easily and quickly.

\section{Antiinfectious Activity}

The most thoroughly researched essential oil with antibacterial properties is the tea tree essential oil (Melaleuca alternifolia). This essential oil was used even by the Aborigines in their folk medicine to treat upper respiratory tract diseases, to heal skin infections and wounds [8]. Numerous reports regarding this oil's properties in vitro indicate that it inhibits the growth of the majority of bacteria in the maximum concentration up to $2 \%$, including strains resistant to antibiotics $[9,10]$. Antibacterial activity has been also reported in many other essential oils [11]. It was observed that Gram-positive bacteria are more susceptible to essential oils than Gram-negative ones, with some exceptions [9].

Thyme oil (Thymus vulgaris), cinnamon oil (Cinamomum spp.) and clove oil (Syzygium aromaticum) are effective in lower concentrations and their spectrum of activity is broad. Their antibacterial effect depends on their composition and on the percentage of particular compounds, which, when appearing together, may increase or decrease their 
own activity. This interaction may be connected the protection of the active substances against enzymatic degradation, transport modification across cell membranes, avoiding mechanisms determining bacteria multiresistance, etc. The same substances divided into fractions may lack the previously observed activity, and their synergistic activity may diminish when trying to isolate particular compounds [1].

Individual compounds of essential oils may also present a strong antibacterial activity. It is assumed that this property depends on the dosage used [9]. The most popular compounds are, in this respect, among others: terpinene, cineole, carvacrol, thymol and cinnamaldehyde.

Numerous reviews concerning the interaction between oils, their components and antibiotics were presented by Langeveld et al. [12]. According to the authors, the synergistic effect of these substances may result from the fact that:

- antibiotics and compounds of essential oils have different target activity (tea tree oil and gentamicin),

- compounds of essential oils inhibit the mechanisms of resistance to antibiotics,

- essential oils affect physicochemical and pharmacokinetic properties of the antibiotic, improving its solubility and bioavailability.

Despite their synergistic activity with antibiotics, compounds of essential oils can also be synergistic with antiseptics. Compounds belonging to the terpene group are commonly used as supplementary substances in preparations applied to the skin, this preparations increased the skin's permeability to substances appearing both as particles and ions [13]. By increasing the penetration of antiseptics through the skin, they reduce the risk of infections following surgeries. Additionally, it has been reported that the main component of the eucalyptus essential oil (1.8-cineol) and the essential oil itself increased the activity of a commonly used disinfectant, chlorhexidine digluconate, against planctonic and biofilm culture of $S$. aureus and C. albicans $[14,15]$.

There are also studies which prove that antibacterial properties of essential oils could be used to modify dressings used in the treatment of chronic infections following surgeries, decubitus ulcers, vein and cancer ulcers. Budzyńska et al. [16] reported that saturating absorption dressings with lemon balm (Melissa officinalis), geranium (Pelargonium odorantissimum), clove (Syzygium aromaticum) or citronella (Cymbopogon nardus) essential oils in concentrations equivalent to the minimal inhibitory concentration (MIC) $(<0.1 \% \mathrm{v} / \mathrm{v})$ present a biocidal effectiveness against germs that have been absorbed by the dressing.
Lipophilicity of essential oils and their compounds is important, because it decides upon the mechanism of action on germs. It enables the interaction with the cell membrane and mitochondrium lipids, which leads to disturbances in the structure of cells and influences membrane transport. The increased permeability of cell envelopes and the excessive loss of important particles and ions can then damage cells $[12,17]$.

Essential oils may also influence other important processes that take place in cells. They inhibit the synthesis of DNA and RNA nucleic acids and the production of proteins, which, among others, regulate gene expression in cells $[1,9]$. They limit or inhibit the activity of enzymes like lipase, coagulase [18], amino-acid decarboxylase [19], and enzymes that break down antibiotics. They reduce the virulence of germs by influencing factors connected with the cell wall or excretion. They also inhibit their synthesis $[18,20]$. By deactivating the membrane efflux pumps, which remove antibiotics and bacteria communication factors outside the cell, they influence the biofilm, enabling its eradication, and they increase the penetration of antibiotics in the biomass. They also influence multidrug resistant strains, because they act multidirectionally and differently than antibiotics [21-23].

Effective and safe antifungal compounds are being sought due to the increasing problem of fungal infections, including severe invasive infections, resistance of fungi to drugs, the toxicity and side effects of used antimycotics. The majority of reports on the activity of essential oils concern Candida strains. Minimal concentration of tea tree oil that inhibits the growth of yeast-like fungi does not exceed $0.125 \mu \mathrm{g} / \mathrm{mL}$, while for 5 'fluorocytosine and amfotericin B it is respectively $\geq 0.25$ and $\geq 1 \mu \mathrm{g} / \mathrm{mL}$ [24]. Common myrrh (Commiphora myrrha), bergamot (Citrus bergamia), ylang ylang (Cananga odorata), lavender (Lavendula officinalis) and Geranium maculatum essential oils, in $0.125-4 \%$ concentrations, also show inhibitory effects [25].

The activity of the majority of essential oils against human pathogenic fungi is considered to be moderate compared to synthetic medicines [26]. However, in the studies on the interaction of oils with antimycotics, the synergy between these compounds has been reported several times. This synergism was presented in the combination of Pelargonium graveolens essential oil with amphotericin B and nystatin against Candida albicans strains [27], Thymus vulgaris essential oil with amphotericin B and myrtle (Myrtus communis) essential oil with amphotericin B against both Candida spp. and Aspergillus niger [28]. Basil (Ocimum sanctum) essential oil revealed synergism with fluconazole and ketokonazole against Candida spp. 
sensitive and resistant to fluconazole. By combining the above preparations in therapy, we could reduce the dosage of drugs, and in this way, minimize their side effects. However, it is necessary to optimally choose the essential oil concentration, because when it is too low, it may even present an antagonistic effect [28].

Anti-fungal properties were also checked on dermatophytes, which are the most resistant to essential oils among fungi. The best growth inhibitors of Trichophyton genus were lemon grass leaves (Cymbopogon citratus) and blue gum (Eucalyptus globulus) essential oils, for which inhibiting concentrations were respectively $0.125-0.25$ and $0.125-1 \mathrm{mg} / \mathrm{mL}$. In combination with ketoconazole, the best results were obtained for the P. graveolens essential oil, which contains geraniol and citronellol [29].

The spread of viral diseases, the limited number of effective drugs and the appearance of resistance to viruses are all factors which prompt the search for new, biologically active, antiviral substances. At the same time, they should present a new mechanism of action. These criteria are met by essential oils, because their components, in contrast to therapeutic preparations used so far, are extracellularly active [7].

Experiments aimed to assess the antiviral activity of essential oils have been most frequently conducted on viruses from the herpes group (herpes simplex virus type 1 and 2 (HSV-1 and HSV-2) [30]. As demonstrated in in vitro studies, this activity is mainly based on the interaction of essential oil components with the virus envelope. It is damaged or modified in places responsible for the adsorption and penetration of the virus into the cell of a host [7, 31]. Consequently, these oils act mostly on enveloped viruses appearing extracellularly or during the adsorption phase, but not inside the cell. Non-enveloped viruses present no or weak susceptibility to essential oils, which was proved, among others, in studies concerning the influence of the eucalyptus essential oil to adenoviruses [7,32].

Compounds of essential oils can also act synergistically with traditional antiviral medicines. It has been reported that eugenole, the main component of clove (Syzygium aromaticum) essential oil, in a concentration of 30-120 $\mu \mathrm{g} / \mathrm{mL}$, increases the effect of low doses of aciclovir [33]. This probably happens due to the different but complementary mode of action of these compounds, among which aciclovir inhibits the replication of virus inside cells and eugenol, acting extracellularly, impedes the penetration of the virus into the cell. It was also observed that some essential oils preserve their inhibitory activity towards viruses resistant to aciclovir. They include ginger (Zingiber officinale), thyme
(Thymus vulgaris), herbaceous (Hyssopus officinalis), and santalum (Santalum album) essential oils. This may suggest that some of these compounds influence another stages of viral life cycle inside infected cells. This phenomenon is proved by tests conducted on herpesviruses with manuka (Leptospermum scoparium) and tree warmwood (Artemisia arborescens) essential oils [34].

In human clinical trials, it has been reported that the tea tree essential oil is beneficial in the treatment of a recurrent herpes labialis. Applied in gel form, in a $6 \%$ concentration, it reduced the average time of the epidermis regeneration from 12.5 to 9 days [35]. This may justify the use of this oil, and other oils, e.g. lemon oil, as base compounds in aromatherapeutic mixtures recommended in cold sores caused by herpes viruses [25].

Positive effects relating to the application of essential oils compounds on HSV-1 and HSV-2 viruses have been also demonstrated in in vivo animal studies. F. Benencia and Courrèges reported that eugenol delayed the development of keratitis in infected mice [33].

An increasing number of studies regarding the activity of essential oils are also concerned with human parasites. Although most of them are based on in vitro studies, they give promising results and hope for new opportunities of treatment. For example, lavender essential oil (Lavandula angustifolia), in a $\leq 1 \%$ concentration, completely eliminates Trichomonas vaginalis [38]. Thymbra capitata and clove tree (Syzygium aromaticum) essential oils inhibit the adherence of trophozoites and they reveal biocidal effectiveness against Giadia lambilia [39]. Thyme essential oil (Thymus vulgaris) reduces the viability of Trypanosoma protoza, which causes African trypanosomiasis and Chagas' disease [39]. Satureja thymbra essential oil acts on larval forms and adult individuals of Plasmodium falciparum, which causes malaria [39]. There are also singular publications in which oils are described as the source of compounds influencing parasitic worms (trematodes, cestodes, nematodes). In one of them it has been reported that compounds of Mentha spp. essential oil present protoscolicidal effect against Echinococcus granulosus tapeworm [40].

Essential oils can also be the source of substances to deplete mite. Rich in eugenole, clove oil (Syzygium aromaticum) is acaricidal to adult mites (Sarcoptes scabiei). These mites, both sensitive and resistant to permethrin, die in low concentration of clove oil within 15 min [41]. However, tea tree oil (Melaleuca alternifolia) was used in the treatment of blepharitis caused by human mites Demodex folliculorum. This treatment involved scrubbing eyelid margin with 10 and $50 \%$ oil solu- 
tion, which proved to be effective; it reduced disease symptoms and the number of mites [42].

Essential oils are also used to control arthropod vectors of parasite diseases, which include ticks, mosquitos, bugs, flies, fleas, lice and other insects. Many essential oils act on different stages of insects' growth: eggs, larval forms, maggots, and adult individuals. Repellents containing eucalyptus (Eucaliptus spp.), nepeta (Nepeta cataria), turmeric (Curcuma longa) or common guava (Psidium guajava) essential oils provide full protection for many hours, while bay tree (Laurus nobilis) or coriander (Coriandrum sativum) essential oils act as efficient fumigants. Pohlit et al. have published the article containing much more additional information on this issue [43].

To date, the use of essential oils in medical practice has been limited. This is due to the lack of therapeutic strategies, resulting from insufficient number of clinical examinations [17]. In the literature, there are only few pieces of in vivo data about the cytotoxicity of essential oils, and their mechanism of tissues penetration, and on the possibility to use different concentrations depending on the manner of application. Currently, low concentrations of essential oils or their compounds are rather additives to ointments, creams, balms, lotions, gels, drops, or other specifics applied externally in skin diseases, aromatherapy, and massages [3, 13]. Compounds of essential oils can be found also in toothpastes and mouthwashes in order to reduce the formation of bacterial plaque [44]. Essential oils may have a positive effect on health, if they are absorbed by the respiratory system mucous membrane, and that is why they tend to be used in inhalations during respiratory tract infections. Lemon oil, despite its antibacterial properties, additionally acts as expectorant, because it increases and thins the secretion by irritating the mucous membrane of bronchi [25]. Researchers, who used the preparation with tea tree essential oil of concentrated monoterpenes fraction (terpen-4-ol alpha consisted of $62-64 \%$ ), have obtained promising results in 2 patients with original tuberculosis. The preparation was inhaled once a day for 10 days. Cultures, tested 4-5 days following the treatment, were negative, and there was a noted clinical improvement, including reduced body temperature, cleared up cough, better appetite and weight gain [45].

Beneficial effects of tea tree essential oil were observed in the therapy supporting the treatment of bone marrow inflammation and chronic wounds infections, as well as in alternative treatment of AIDS patients suffering from oropharyngeal candidiasis [46]. The mixture of essential oils and antibiotics was used in patients with cancer ulcer infections [44].

\section{Toxicity and Resistance to Essential Oils}

Essential oils are, however, not devoid of side effects, which may include contact allergies, dermatitis, stomatitis, and ototoxicity. In the case of systemic administration, essential oils may cause kidney irritation, changes in intestinal mucous membrane, or they may result in neuro- and hepatotoxicity [3, 47]. Side effects are connected with the dosage used, so essential oils are not recommended to be used in concentrations higher than $10 \%$ and to be overused by the systemic dose of $0.3 \mathrm{mg} / \mathrm{kg} /$ day [1, 47]. Cytotoxic activity and strong irritation properties can be also induced by light, so that is why it is advised to avoid sunlight for several hours after applying essential oils of high phototoxicity such as lemon essential oil [25]. The processes of oxidation may be partially responsible for the toxicity of essential oils, if they are stored inappropriately or too long. There are reports indicating that when overusing essential oils, some of their ingredients may indirectly stimulate the development of cancer. This has been demonstrated in animal studies on estragole, compound of Ocimum basilicum and Artemisia dracunculus essential oils, and D-limonene, compounds of essential oils from plants of Citrus genus origin [11]. On the other hand, essential oils and some of their compounds have antimutagenic and anti-cancer properties, which has been reported in numerous publications [11]. Side effects of essential oils do not exclude them as a source of medical substances. Their toxic effect may be limited by modifying the essential oils administration with the use of liposomes [48].

Another significant problem, which should be taken into consideration when planning the use of essential oils in clinical practice is the possibility of developing resistance or reduced sensitivity of bacteria to particular essential oils and their components. Currently, in laboratory tests, essential oils are tested on the group of most pathogenic germs (S. aureus, E. coli, A. baumanii, etc). They are susceptible to low concentrations of these substances. However, it cannot be excluded that in our environment there are bacteria naturally resistant to active compounds of essential oils. If essential oils are commonly used as medical preparations, there is a risk that resistance to them will quickly develop and spread. Pseudomonas aeruginosa is an example of bacteria with increased tolerance to the tea tree essential oil compounds. Due to the efflux pump MexAB-OprM, these bacteria extrude from cells not only many antibiotics, but also other compounds of anti-microbial property, includ- 
ing active ingredients of the Melaleuca alternifolia essential oil such as terpinene-4-ol, a-terpineol or 1.8-cineol [49].

Some authors claim that due to extensive properties of essential oils, the risk of developing resistance to them is low. McMahon et al. have reported that in bacteria exposed to subinhibitory concentrations of essential oils, the decrease of susceptibility to these oils develops easily [50]. The level of resistance is usually regarded as low, and this phenomenon is of reversible character and depends on the type of bacteria and the examined oil. There is also a risk that essential oils administered in therapy when combined with antibiotics may cause the induction of resistance to used drugs. Induction of this phenomenon has been reported in the case of tea tree essential oil [50].

\section{Conclusions}

The number of articles on the biocidal effectiveness of essential oils is constantly increasing. These plant products are popular, because they may also have spasmolytic, anti-inflammatory and analgesic properties and they have a direct and beneficial influence on the central nervous system as well as the human mental state [45]. The process of obtaining essential oils is not expensive, so essential oils used as phytopharmaceuticals could reduce the costs of medical treatment. However, before this will be possible, it is necessary to develop quality standards of obtaining and using these plant products, so that they may provide safe and effective assistance in the fight against human pathogens.

\section{References}

[1] Efferth T, Koch E: Complex interactions between phytochemicals. The multi-target therapeutic concept of phytotherapy. Curr Drug Targ 2011, 12, 1-11.

[2] Radulović NS, Blagojević PD, Stojanović-Radić ZZ, Stojanowić NM: Antimicrobial plant metabolites: Structural diversity and mechanism of action. Curr Med Chem 2013, 20, 932-952.

[3] Van Wyk BE, Wink M: Rośliny lecznicze świata. MedPharm Polska, Wrocław 2008.

[4] Chrząstek L, Dondela B: The use of terpene alcohols in cosmetics. Pol J Cosmetol 2008, 11, 307-312.

[5] Hyldgaard M, Mygind T, Meyer RL: Essential oils in food preservation: Mode of action, synergies, and interactions with food matrix components. Front Microbiol 2012, 3, 12.

[6] Warnke PH, Terheyden H, Açil Y, Springer IN, Sherry E, Reynolds M, Russo PAJ, Bredee JP, Podschun R: Tumor smell reduction with antibacterial essential oils. Cancer 2004, 100, 879-880.

[7] Reichling J, Schnitzler P, Suschke U, Saller R: Essential oils of aromatic plants with antibacterial, antifungal, antiviral, and cytotoxic properties - an overview. Forsch Komplementmed 2009, 16, 79-90.

[8] Carson CF, Hammer KA, Riley TV: Melaleuca alternifolia (tea tree) oil: A review of antimicrobial and other medicinal properties. Clin Microbiol Rev 2006, 19, 50-62.

[9] Kalemba D, Kunicka A: Antibacterial and antifungal properties of essential oils. Curr Med Chem 2003, 10, 813-829.

[10] Banes-Marshall L, Cawley P, Phillips CA: In vitro activity of Melaleuca alternifolia (tea tree) oil against bacterial and Candida spp. isolates from clinical speciments. Br J Biomed Sci 2001, 58, 139-145.

[11] Bakkali F, Averbeck S, Averbeck D, Idaomar M: Biological effects of essential oils - a review. Food Chem Toxicol 2008, 46, 446-475.

[12] Langeveld WT, Veldhuizen EJA, Burt SA: Synergy between essential oil components and antibiotics: A review. Crit Rev Microbiol 2014, 40, 76-94.

[13] Cal K: Postdoc. Thesis: Wpływ rodzaju nośnika oraz właściwości fizykochemicznych terpenów na ich przenikanie do warstw skóry ludzkiej. Medical University of Gdańsk. Gdańsk. Poland 2006.

[14] Hendry ER, Worthington T, Conway BR, Lambert PA: Antimicrobial efficacy of eucalyptus oil and 1,8-cineole alone and in combination with chlorhexidine digluconate against microorganisms grown in planktonic and biofilm cultures. J Antimicrob Chem 2009, 64, 1219-1225.

[15] Karpenen TJ, Conway BR, Worthington T, Hilton AC, Elliott TS, Lambert PA: Enhanced chlorhexidine skin penetration with eucalyptus oil. BMC Infect Dis 2010, 10, 278.

[16] Budzyńska A, Sadowska B, Więckowska-Szakiel M, Różalska B: In vitro efficacy analysis of absorbent dressing modified with essential oils, against Staphylococcus aureus and Candida albicans. Med Dośw Mikrobiol 2013, 65, 77-86.

[17] Solórzano-Santos F, Miranda-Novales MG: Essential oils from aromatic herbs as antimicrobial agents. Curr Opin Biotech 2012, 23, 136-141.

[18] Carneiro de Barros J, Lucia da Conceição M, Gomes Neto NJ, Vieira da Costa AC, Pinto Siqueira J, Diniz Basílio I, Leite de Souza E: Interference of Origanum vulgare L. essential oil on the growth and some physiological characteristics of Staphylococcus aureus strains isolated from foods. LWT - Food Sci Technol 2009, 42, 1139-1143.

[19] Wendakoon CN, Sakaguchi M: Inhibition of amino acid decarboxylase activity of Enterobacter aerogenes by active components in spices. J Food Prot 1995, 58, 280-283.

[20] Hołderna-Kędzia E: Activity of essential oil substances on bacteria and fungi. Post Fitoter 2010, 1, 3-8.

[21] Szabó MA, Varga GZ, Hohmann J, Schelz Z, Szegedi E, Amaral L, Molnár J: Inhibition of quorum-sensing signals by essential oils. Phytother Res 2010, 24, 782-786. 
[22] Hemaiswarya S, Kruthiventi AK, Doble M: Synergism between natural products and antibiotics against infectious diseases. Phytomedicine 2008, 15, 639-652.

[23] Budzyńska A, Różalska B: Potencjalne wykorzystanie roślinnych olejków eterycznych w zwalczaniu zakażeń z udziałem biofilmów drobnoustrojów. Życie Wet 2012, 87, 213-215.

[24] Oliva B, Piccirilli E, Ceddia T, Pontieri E, Aureli P, Ferrini AM: Antimycotic activity of Melaleuca alternifolia essential oil and its major components. Lett Appl Microbiol 2003, 37, 185-187.

[25] Borowiecka J, Motyl M: Lemon oil in health care, aromatherapy and cosmetics. Pol J Cosmetol 2007, 10, 100-108.

[26] Shin S, Kang CA: Antifungal activity of the essential oil of Agastache rugosa Kuntze and its synergism with ketoconazole. Lett Appl Microbiol 2003, 36, 111-115.

[27] Rosato A, Vitali C, Piarulli M, Mazzotta M, Argentieri MP, Mallamaci R: In vitro synergic efficacy of the combination of nystatin with the essential oils of Origanum vulgare and Pelargonium graveolens against some Candida species. Phytomedicine 2009, 16, 972-975.

[28] Giordani R, Regli P, Kaloustian J, Mikaïl C, Abou L, Portugal H: Antifungal effect of various essential oils against Candida albicans. Potentiation of antifungal action of amphotericin B by essential oil from Thymus vulgaris. Phytother Res 2004, 18, 990-995.

[29] Shin S, Lim S: Antifungal effects of herbal essential oils alone and in combination with ketoconazole against Trichophyton spp. J Appl Microbiol 2004, 97, 1289-1296.

[30] Nowak A: The inhibitory effect of essential oil on HSV-1 and HSV-2 virus. Post Fitoter 2011, 4, $243-247$.

[31] Astani A, Reichling J, Schnitzler P: Comperative study on the antiviral activity of selected monoterpens derived from essential oil. Phytother Res 2010, 24, 673-679.

[32] Cermelli C, Fabio A, Fabio G, Quaglio P: Effect of eucalyptus essential oil on respiratory bacteria and viruses. Curr Microbiol 2008, 56, 89-92.

[33] Benencia F, Courrèges MC: In vitro and in vivo activity of eugenol on human herpesvirus. Phytother Res 2000, $14,495-500$.

[34] Saddi M, Sanna A, Cottiglia F, Chisu L, Casu L, Bonsignore L, De Logu A: Antiherpes activity of Artemisia arborescens essential oil and inhibition of lateral diffusion in Vero cells. Ann Clin Microbiol Antimicrob 2007, 6, 1-10.

[35] Carson CF, Ashton L, Dry L, Smith DW, Riley TV: Melaleuca alternifolia (tea tree) oil gel (6\%) for the treatment of recurrent herpes labialis. J Antimicrob Chemother 2001, 48, 450-451.

[36] Moon T, Wilkinson JM, Cavanagh HM: Antiparasitic activity of two Lavandula essential oils against Giardia duodenalis, Trichomonas vaginalis and Hexamita inflata. Parasitol Res 2006, 99, 722-728.

[37] Machado M, Dinis AM, Salgueiro L, Custódio JB, Cavaleiro C, Sousa MC: Anti-Giardia activity of Syzygium aromaticum essential oil and eugenol: Effects on growth, viability, adherence and ultrastructure. Exp Parasitol $2011,127,732-739$.

[38] Santoro GF, Cardoso MG, Guimarães LGL, Salgado APSP, Menna-Barreto RFS, Soares MJ: Effect of oregano (Origanum vulgare L.) and thyme (Thymus vulgaris L.) essential oils on Trypanosoma cruzi (Protozoa: Kinetoplastida) growth and ultrastructure. Parasitol Res 2007, 100, 783-790.

[39] Dell'Agli M, Sanna C, Rubiolo P, Basilico N, Colombo E, Scaltrito MM, Ndiath MO, Maccarone L, Taramelli D, Bicchi C, Ballero M, Bosisio E: Anti-plasmodial and insecticidal activities of the essential oils of aromatic plants growing in the Mediterranean area. Malar J 2012, 2, 219.

[40] Maggiore MA, Albanese AA, Gende LB, Equaras MJ, Denegri GM, Elissondo MC: Anthelmintic effect of Mentha spp. essential oils on Echinococcus granulosus protoscoleces and metacestodes. Parasitol Res 2012, 110, 1103-1112.

[41] Pasay C, Mounsey K, Stevenson G, Davis R, Arlian L, Morgan M, Vyszenski-Moher D, Andrews K, McCarthy J: Acaricidal activity of eugenol based compounds against scabies mites. PloS One 2010, 5, e12079. DOI: 10.1371/ journal.pone.0012079.

[42] Koo H, Kim TH, Kim KW, Wee SW, Chun YS, Kim JC: Ocular surface discomfort and Demodex: Effect of tea tree oil eyelid scrub in Demodex blepharitis. J Korean Med Sci 2012, 27, 1574-1579.

[43] Pohlit AM, Rezende AR, Lopes Baldin EL, Lopes NP, Neto VF: Plant extracts, isolated phytochemicals, and plantderived agents which are lethal to arthropod vectors of human tropical diseases - a review. Planta Med 2011, 77, 618-630.

[44] Warnke PH, Sherry E, Russo PAJ, Açil Y, Wiltfang J, Sivananthan S, Sprengel M, Roldàn JC, Schubert S, Bredee JP, Springer ING: Antibacterial essential oils in malodorous cancer patients: Clinical observations in 30 patients. Phytomedicine 2006, 13, 463-467.

[45] Sherry E, Reynolds M, Sivananthan S, Mainawalala S, Warnke PH: Inhalational phytochemicals as possible treatment for pulmonary tuberculosis: Two case reports. Am J Infect Control 2004, 32, 369-370.

[46] Warnke PH, Sherry E: The battle against multi-resistant strains: Renaissance of antimicrobial essential oils as a promising force to fight hospital-acquired infections. J Cranio Maxillofac Surg 2009, 37, 392-397.

[47] Pisseri F, Bertoli A, Pistelli P: Essential oils in medicine: Principles of therapy. Parassitologia 2008, 50, 89-91.

[48] Low WL, Martin C, Hill DJ, Kenward MA: Antimicrobial efficacy of liposome-encapsulated silver ions and tea tree oil against Pseudomonas aeruginosa, Staphylococcus aureus and Candida albicans. Lett Appl Microbiol 2013, 57, 33-39.

[49] Papadopoulos CHJ, Carson CHF, Chang BJ, Riley TV: Role of the MexAB-OprM efflux pump of Pseudomonas aeruginosa in tolerance to tea tree (Melaleuca alternifolia) oil and its monoterpene components terpinen-4-ol, 1,8-cineole, and a-terpineol. Appl Environ Microb 2008, 74, 1932-1935.

[50] McMahon MAS, Tunney MM, Moore JE, Blair IS, Gilpin DF, McDowell DA: Changes in antibiotic susceptibility in staphylococci habituated to sub-lethal concentrations of tea tree oil (Melaleuca alternifolia). Lett Appl Microbiol 2008, 47, 263-268. 


\section{Address for correspondence:}

Elżbieta Piątkowska

Department of Pharmaceutical Microbiology and Parasitology

Wroclaw Medical University

ul. Borowska 211a

50-556 Wrocław

Poland

Tel.: +48 717840675

E-mail: litwinekela@wp.pl

Conflict of interest: None declared

Received: 15.09 .2014

Revised: 9.10.2014

Accepted: 5.11.2014 